\title{
Uji Pemanfaatan Pupuk Organik Cair Lindi dengan Penambahan Bakteri Starter Terhadap Pertumbuhan Tanaman Hortikultura (Solanum Melongena dan Capsicum Frutescens)
}

\author{
Dania Dwi Dimiati dan Wahyono Hadi \\ Departemen Teknik Lingkungan, Fakultas Teknik Sipil dan Perencanaan, Institut Teknologi Sepuluh Nopember \\ (ITS) \\ e-mail:wahyonohadi@yahoo.com
}

\begin{abstract}
Abstrak-Air lindi apabila tidak dikelola dengan baik maka akan menimbulkan dampak negatif karena mengandung zat pencemar organik dan anorganik yang tinggi. Namun, air lindi memilik kandungan unsur hara makro berkadar tinggi. Selain itu, saat ini penggunaan pupuk anorganik yang berlebihan akan mengurangi tingkat kesuburan tanah dan menurunnya produktivitas tanaman. Maka dilakukan penelitian untuk mengolah air lindi yang berasal dari Stasiun Peralihan Antara (SPA) Rangkah Surabaya untuk menghasilkan pupuk cair organik dengan memanfaatkan bakteri starter melalui proses fermentasi. Variabel yang digunakan adalah variasi pengenceran lindi dan penambahan bakteri starter (cair dan bubuk). Tahapan persiapan terdiri atas uji karakteristik lindi awal serta pembuatan media penanaman. Kemudian tahap utama terdiri pembuatan reaktor, proses fermentasi, uji Total Plate Count (TPC), uji karakteristik hasil fermentasi, dan pengamatan pertumbuhan tanaman dengan pemberian pupuk organik cair lindi. Tanaman yang digunakan sebagai bahan uji adalah terong (Solanum melongena) dan cabai (Capsicum frutescens). Hasil penelitian menunjukkan interaksi antara faktor penambahan bakteri dan pengenceran lindi berpengaruh signifikan terhadap peningkatan amonium dan nitrat hasil fermentasi. Reaktor yang memiliki pengaruh paling signifikan adalah B3 (untuk starter serbuk) dan C3 (untuk starter cair). Sedangkan yang memiliki konsentrasi optimum penambahan bakteri adalah reaktor B3 dan D1. Pemberian pupuk organik cair variasi B3 dan D1 pada tanaman seharusnya memberikan respon cepat terhadap laju pertumbuhan tanaman, namun pada hasil pengamatan di lapangan menunjukkan hasil yang berbeda.
\end{abstract}

Kata Kunci-Bakteri Starter, Capsicum frutescens, lindi, Pupuk Cair Organik, Solanum melongena.

\section{PENDAHULUAN}

$\mathrm{L}$ INDI yang dihasilkan dari proses pemadatan sampah di SPA Rangkah saat ini ditampung dalam bak penampung lindi dan dilakukan proses penyedotan secara berkala oleh petugas Dinas Kebersihan dan Pertamanan (DKP) Kota Surabaya untuk dibawa ke Instalasi Pengolahan Lindi (IPL) di TPA [1]. Lindi yang ditampung ini berpotensi untuk diolah dan dimanfaatkan lebih lanjut, karena mengandung unsur hara yang berkadar tinggi.

Lindi merupakan limbah cair yang timbul akibat masuknya air ke dalam timbunan sampah dan bersifat melarutkan unsur- unsur kimiawi terlarut termasuk materi organik hasill dekomposisi [2]. Air lindi banyak mengandung unsur - unsur yang dibutuhkan tanaman, diantaranya organik Nitrogen (10$600 \mathrm{mg} / \mathrm{l})$, Amonium Nitrogen (10-800 mg/l), Nitrat (5-40 $\mathrm{mg} / \mathrm{l})$, Fosfor Total (1-70 mg/l), dan Total Besi (50-600 mg/l) [3].

Limbah cair dari bahan organik bisa dimanfaatkan menjadi pupuk. Penggunaan pupuk dari limbah ini dapat membantu memperbaiki struktur dan kualitas tanah [4]. Karena penggunaan pupuk anorganik secara berlebihan dalam jangka waktu yang lama dapat berakibat buruk pada kondisi tanah. Tanah menjadi cepat mengeras, kurang mampu menyimpan air (tingkat kesuburan tanah menurun), dan cepat menjadi asam yang pada akhirnya menurunkan produktivitas tanaman [5].

Salah satu cara yang dilakukan untuk mengatasi permasalahan di atas adalah dengan menerapkan pertanian organik untuk mencegah semakin merosotnya kesuburan tanah. Komoditas tanaman yang banyak dibudidayakan dalam pertanian organik adalah terong (Solanum melongena) dan cabai (Capsicum frutescens). Pupuk organik dapat dijadikan salah satu alternatif pengganti pupuk anorganik yang selama ini umum digunakan oleh para petani.

Maka dari itu, lindi dari SPA Rangkah dapat dimanfaatkan sebagai pupuk organik cair melalui proses fermentasi dengan melibatkan peran mikroorganisme, sehingga dapat menjadi produk pertanian yang bermanfaat. Dengan penambahan bakteri starter yaitu bakteri penambat nitrogen (Azospirillum $s p)$ pada proses fermentasi, diharapkan lindi mengandung kadar unsur mikro dan makro yang sesuai untuk tanaman.

\section{METODE PENELITIAN}

\section{A. Waktu dan Tempat Penelitian}

Waktu pelaksanaan penelitian ini dilakukan pada awal bulan Februari hingga bulan Mei 2017 di Laboratorium Teknologi Pemulihan Air dan Laboratorium Limbah Padat dan B3 Departemen Teknik Lingkungan FTSP ITS.

\section{B. Pengambilan Sampel Air Lindi SPA Rangkah}

Pengambilan sampel air lindi dilakukan dalam satu hari menggunakan jeriken plastik ukuran lima liter. 


\section{Uji Karakteristik Lindi Awal}

Uji karakteristik lindi dilakukan untuk mengetahui unsur apa yang terkandung di dalam lindi di SPA Rangkah. Uji karakteristik lindi yang dilakukan adalah uji amonium, nitrat, BOD, dan COD.

\section{Pengujian Awal Jumlah Koloni}

Pada tahap ini diuji dahulu bioaktivator serbuk dan cair yang berisi bakteri penambat $\mathrm{N}$ (Azospirillum $s p$ ) melalui uji Total Plate Count (TPC) untuk mengetahui jumlah koloni awal yang ada pada bioaktivator. Sedangkan pada bioaktivator cair juga dilakukan uji identifikasi dengan pengujian pada Laboratorium Balai Penelitian dan Konsultasi Industri (BPKI).

\section{E. Pembuatan Media Pembibitan dan Penanaman}

Pembuatan media ini disiapkan sebanyak 32 reaktor polybag terdiri atas 6 reaktor kontrol, 6 reaktor yang ditambahkan pupuk cair lindi A (bakteri starter serbuk), 6 reaktor yang ditambahkan pupuk cair lindi B (bakteri starter cair), serta 2 reaktor yang ditambahkan pupuk cair kimia merek NPK. Jumlah 32 reaktor tersebut akan diperlakukan duplo, sehingga dibutuhkan 64 reaktor tanaman.

Pernyemaian dengan menggunakan media tanah di polybag ukuran $20 \times 20 \mathrm{~cm}$ yaitu tanah kebun dari toko tanaman (lempung berpasir) dan tidak memberi campuran pupuk.

Bibit dinyatakan siap ditanam pada saat berumur 25 - 30 hari setelah semai atau memiliki 3-4 helai daun. Sebelum bibit dipindah, tanaman dilakukan sortasi lebih dahulu untuk memilih bibit yang sehat dan seragam (homogen). Setelah itu bibit dipindahkan ke polibag ukuran $40 \mathrm{~cm} \times 40 \mathrm{~cm}$ yang berisi tanah kebun, dimana satu polybag berisi satu tanaman.

\section{F. Pembuatan Variasi Penelitian}

Air lindi yang diambil dari SPA Rangkah diencerkan dengan variasi pengenceran 50x, 75x, 100x, dalam $10 \mathrm{ml}$ lindi. Sehingga akan didapat hasil pengenceran yaitu $500 \mathrm{ml}, 750$ $\mathrm{ml}$, dan $1000 \mathrm{ml}$.

Penambahan bakteri starter cair yaitu $5 \mathrm{cc}(5 \mathrm{ml})$ dan $10 \mathrm{cc}$ $(10 \mathrm{ml})$ sedangkan bakteri starter serbuk bakteri $0,5 \mathrm{~g}$ dan $1 \mathrm{~g}$ masing - masing pada $500 \mathrm{ml}, 750 \mathrm{ml}$, dan $1000 \mathrm{ml}$ air lindi. Matriks penelitian dapat dilihat pada tabel 1 dan 2 dibawah ini

Tabel 1.

Matriks penelitian untuk bakteri starter serbuk

\begin{tabular}{cccc}
\hline \hline Pengenceran lindi & $50 \times(1)$ & $75 \times(2)$ & $\begin{array}{c}100 \mathrm{x} \\
(3)\end{array}$ \\
\hline Konsentrasi bakteri & A1 & A2 & A3 \\
$0,5 \mathrm{gr}(\mathrm{A})$ & $\mathrm{B} 1$ & $\mathrm{~B} 2$ & $\mathrm{~B} 3$ \\
\hline \hline
\end{tabular}

Tabel 2.

Matriks penelitian untuk bakteri starter cair

\begin{tabular}{cccc}
\hline \hline Pengenceran lindi & $50 \mathrm{x}(1)$ & $75 \mathrm{x}(2)$ & $\begin{array}{c}100 \mathrm{x} \\
(3)\end{array}$ \\
\hline Konsentrasi bakteri & $\mathrm{C} 1$ & $\mathrm{C} 2$ & $\mathrm{C} 3$ \\
$5 \mathrm{ml}(\mathrm{C})$ & $\mathrm{D} 1$ & $\mathrm{D} 2$ & $\mathrm{D} 3$ \\
\hline $10 \mathrm{ml}(\mathrm{D})$ & & &
\end{tabular}

\section{G. Proses Fermentasi}

Fermentasi dilakukan selama 14 hari di reaktor botol kaca 1 liter (botol bensin yang telah dibersihkan). Selama proses fermentasi, tutup botol bensin diberi lubang untuk slang pastik agar gas hasil fermentasi dapat bebas keluar.

\section{H. Uji Total Plate Count (TPC)}

Uji jumlah koloni bakteri dilakukan selama proses fermentasi, yaitu pada hari hari ke-7 dan hari ke-14. Uji ini dimaksudkan untuk mengetahui tingkat pertumbuhan bakteri pada pupuk cair organik lindi melalui jumlah koloni yang terhitung. Pada persyaratan teknis minimal pupuk organik cair, standar baku bakteri Azospirillum sp. yang digunakan pada penelitian kali ini adalah $\geq 10^{8} \mathrm{cfu} / \mathrm{ml}$.

\section{Uji Amonium, Nitrat, BOD, dan COD}

Analisis yang dilakukan sama dengan uji karakteristik awal lindi, untuk mengetahui kandungan amonium, nitrat, BOD, dan COD pada hasil fermentasi. Kemudian dilakukan analisis anova (uji signifikansi) terhadap hasil pupuk organik cair lindi untuk melihat pengaruh pemberian bakteri dan konsentrasi lindi yang telah diberikan.

\section{J. Pemberian Pupuk Organik Cair Lindi pada Tanaman Uji}

Pemupukan bisa dilakukan setelah usia tanaman 2 minggu hari setelah tanam (HST) dengan mendapat tiga perlakuan, yaitu pemberian pupuk cair lindi, dengan pembanding pupuk anorganik, dan kontrol (hanya dengan penambahan lindi yang telah diencerkan tanpa penambahan bakteri starter). Pupuk pembanding yang akan digunakan adalah pupuk anorganik yang ada dipasaran yaitu pupuk NPK.

Pemberian pupuk dilakukan dengan dosis sebanyak $250 \mathrm{~mL}$ untuk satu tanaman uji. Pemberian pupuk dilakukan selama seminggu sekali sekali, selama 4 minggu penyiraman (disesuaikan dengan lama pengamatan pertumbuhan tanaman yaitu 30 hari).

\section{K. Pengamatan Pertumbuhan Tanaman}

Pertumbuhan tanaman dilihat dari perbandingan jumlah daun dan tinggi tanaman. Pengamatan tinggi tanaman dan jumlah daun dilakukan setiap tiga hari sekali sejak pemupukan. Pengamatan dilakukan selama tiga hari sekali selama 30 hari.

\section{HASIL DAN PEMBAHASAN}

\section{A. Uji Karakteristik Lindi Awal}

Tahap uji karakteristik awal lindi ini dilakukan untuk mengetahui unsur apa saja yang terkandung di dalam lindi di SPA Rangkah. Hasil karakteristik lindi awal dapat dilihat pada tabel 3 berikut:

Tabel 1

Hasil karakteristik awal lindi SPA Rangkah

\begin{tabular}{cc}
\hline \hline Kandungan unsur dalam air lindi & Nilai \\
\hline BOD & $500 \mathrm{mg} / \mathrm{l}$ \\
COD & $1920 \mathrm{mg} / \mathrm{l}$ \\
Amonium Nitrogen & $60 \mathrm{mg} / \mathrm{l}$ \\
Nitrat Nitrogen & $5,028 \mathrm{mg} / \mathrm{l}$ \\
\hline \hline
\end{tabular}


Dari hasil uji karakteristik awal tersebut, dapat diketahui nilai BOD dan COD melebihi nilai baku mutu lindi menurut Peraturan Menteri Lingkungan Hidup dan Kehutanan Nomor P.59/Menlhk/ Setjen/Kum.1/7/2016 tentang baku mutu lindi bagi usaha dan/atau kegiatan tempat pemrosesan akhir sampah bahwa kadar paling tinggi untuk BOD sebesar $150 \mathrm{mg} / \mathrm{L}$, dan COD sebesar $300 \mathrm{mg} / \mathrm{L}$.

Fermentasi anerobik dapat menurunkan nilai BOD dan COD pada lindi. Semakin lama waktu proses anaerobik mengakibatkan tingkat penurunan BOD dan COD semakin mendekati nilai ambang batas yang aman untuk dikembalikan ke lingkungan [6].

Kandungan amonium dan nitrat yang cukup tinggi pada lindi SPA Rangkah berasal dari proses degradasi bahan organik yang terjadi [7]. Dari hasil tersebut, untuk nilai $\mathrm{N}$ awal pada lindi adalah $0,006 \%$. Sedangkan standar mutu $\% \mathrm{~N}$ ( $\mathrm{N}$ total terdiri atas $\mathrm{N}$-organik, amonium nitrogen, dan nitrat nitrogen) dalam persyaratan teknis minimal pupuk cair organik adalah 3 - 6\%. Meskipun masih jauh dari standar baku, namun kandungan $\mathrm{N}$ (amonium nitrogen dan nitrat nitrogen) ini berpotensi untuk dimanfaatkan sebagai pupuk organik cair.

\section{B. Uji Awal Jumlah Koloni Bakteri}

Untuk bioaktivator serbuk, pada cawan petri dengan nilai pengenceran $10^{-6}$, terbaca 30 koloni. Berdasarkan teori perhitungan koloni bakteri [8] jumlah koloni yang dapat dihitung adalah diantara $30-300$ koloni (CFU). Sehingga, dari hasil uji awal koloni pada biokativator serbuk dengan pengenceran $10^{-6}$ dapat dihitung jumlahnya (masuk range) dan didapat jumlah koloni $30 \times 10^{6} \mathrm{cfu} / \mathrm{ml}$.

Sedangkan untuk bioaktivator cair juga dilakukan uji identifikasi dan jumlah koloni bakteri Azospirillum sp (diuji pada Laboratorium Balai Penelitian dan Konsultasi Industri). Metode yang digunakan melalui proses isolasi dengan menggunakan media selektif, yaitu medium semi padat Nitrogen Free Bromthymolblue (NFB). Untuk hasil pembacaan jumlah koloni pada bioaktivator cair adalah 9,6 x $10^{4} \mathrm{cfu} / \mathrm{ml}$. Dari pembacaan hasil koloni yang terbentuk, koloni Azospirillum sp berbentuk circular (bulat), permukaan flat (datar) dan ada yang sedikit timbul (raised), bertepi entire melingkar rata, berukuran kecil - kecil, dan berwarna putih [9].

\section{Uji Total Plate Count (TPC)}

Perhitungan jumlah koloni bakteri dilakukan pada hari ke-7 dan hari ke-14 masing - masing diamati saat 24 jam dan 48 jam setelah diinkubasi. Grafik hasil pengamatan jumlah koloni bakteri starter serbuk dapat dilihat pada Gambar 1 berikut ini :

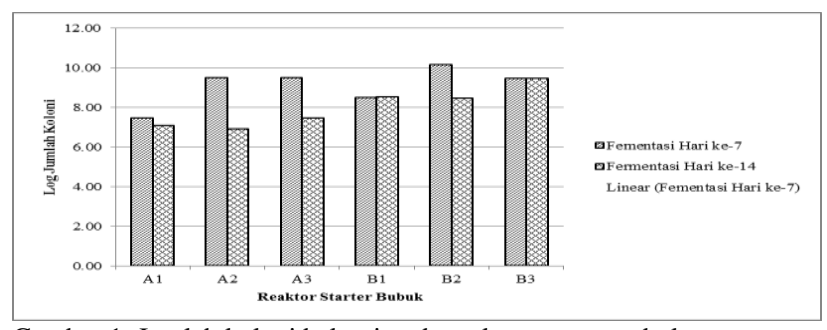

Gambar 1. Jumlah koloni bakteri pada reaktor starter serbuk.
Berdasarkan Gambar 1 dapat diketahui bahwa rata-rata bakteri pada reaktor uji mengalami penurunan jumlah koloni dari hari ke-7 hingga hari hari ke-14, kecuali pada reaktor B1 mengalami kenaikan meskipun tidak terlalu tinggi. Dimana reaktor B1 merupakan reaktor dengan pengenceran terkecil, namun dengan penambahan bakteri serbuk paling besar. Sehingga jumlah bakteri yang masih bertahan selama proses fermentasi masih cukup banyak.

Perlakuan pengenceran dan penambahan bioaktivator mengandung bakteri yang dilakukan berpengaruh pada jumlah koloni bakteri yang ada pada reaktor uji. Dari keenam reaktor uji yang ditambahkan bioaktivator serbuk, bakteri masih dapat hidup dan berkembang biak pada pengamatan 48 jam pada hari ke-14. Walaupun pertumbuhannya tidak terlalu tinggi. Hal ini menunjukkan bahwa bakteri masih dapat hidup pada reaktor hingga fermentasi hari ke-14 walaupun jumlahnya fluktuatif.

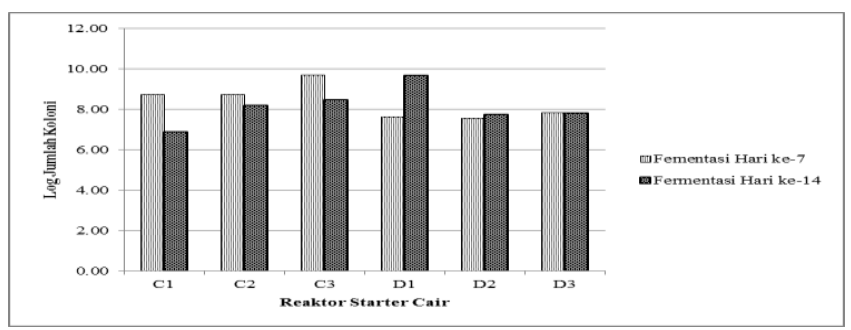

Gambar 2. Jumlah koloni bakteri pada reaktor starter cair.

Sedangkan pada reaktor dengan penambahan bioaktivator cair (gambar 2), dapat diketahui bahwa hampir semua reaktor uji mengalami fluktuasi jumlah koloni bakteri dari hari ke-7 hingga hari ke-14 kecuali pada reaktor uji D1 (reaktor uji yang mendapatkan perlakuan penambahan bioaktivator cair $10 \mathrm{~mL}$ dengan pengenceran lindi sebesar 50 kali) dan reaktor D2 (penambahan bakteri $10 \mathrm{ml}$ pada pengenceran lindi 75 kali) yang mengalami kenaikan jumlah koloni dari hari ke-7 hingga hari ke-14. Jumlah pengenceran yang kecil serta penambahan boaktivator bakteri dengan volume yang relatif besar, mengakibatkan jumlah koloni bakteri semakin meningkat pula.

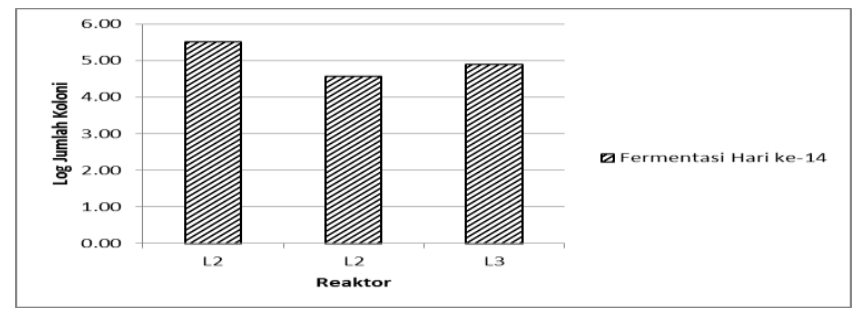

Gambar 3. Jumlah koloni bakteri pada reaktor control.

Kemudian untuk reaktor kontrol dapat dilihat pada gambar 3, jumlah koloni bakteri yang teramati tidak terlalu banyak. Dari jumlah koloni yang terhitung ini, dapat dilihat bahwa didalam lindi sendiri sudah terdapat kandungan bakteri tetapi jumlahnya masih lebih sedikit daripada hasil reaktor dengan penambahan bakteri cair maupun serbuk. Sehingga, lindi sendiri sudah berpotensi untuk dijadikan pupuk organik cair dengan kandungan bakteri yang ada hanya perlu ditingkatkan jumlahnya untuk hasil pupuk yang lebih baik. 


\section{Uji BOD dan COD}

Parameter BOD dan COD diukur di akhir proses fermentasi hari ke-14. Nilai BOD dan COD hasil pengukuran di akhir fermentasi menunjukkan hasil penurunan di semua reaktor jika dibandingkan dengan kadar BOD dan COD awal lindi sebelum dilakukan proses fermentasi. Proses pemecahan atau degradasi senyawa organik yang terjadi pada reaktor uji menjadi senyawa yang lebih sederhana akan menurunkan nilai COD. Penurunan kandungan senyawa organik tersebut, disebabkan oleh aktivitas mikroorganisme di dalam reaktor [10]. Hasil penurunan BOD dan COD dapat dilhat pada Gambar 4 dan 5 berikut ini.

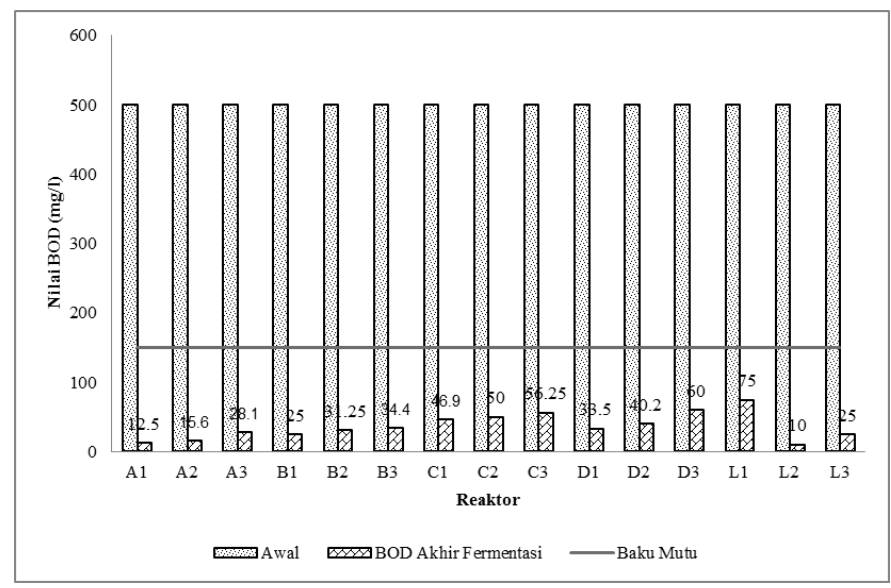

Gambar 4. Hasil uji BOD.

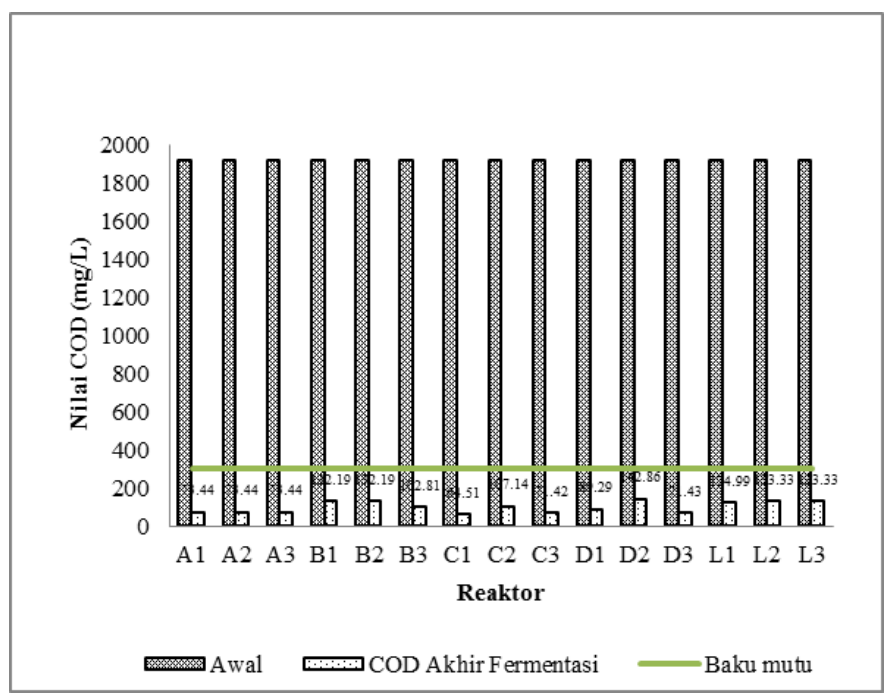

Gambar 5. Hasil uji COD.

Nilai BOD dan COD pada akhir proses fermentasi telah memenuhi telah memenuhi baku mutu yang disyaratkan oleh Peraturan Menteri Lingkungan Hidup dan Kehutanan Nomor P.59/Menlhk/Setjen/Kum.1/7/2016 tentang baku mutu lindi bagi usaha dan/atau kegiatan tempat pemrosesan akhir sampah bahwa kadar paling tinggi untuk BOD sebesar $150 \mathrm{mg} / \mathrm{L}$, dan COD sebesar $300 \mathrm{mg} / \mathrm{L}$. Dengan demikian, BOD dan COD hasil pengukuran menunjukkan bahwa pupuk organik cair lindi pada semua reaktor uji dapat dikembalikan ke lingkungan atau diberikan pada tanaman.

\section{E. Uji Amonium dan Nitrat}

Pengukuran dilakukan pada akhir proses fermentasi (hari ke-14) untuk mengetahui pengaruh penambahan bakteri starter pada lindi yang telah diencerkan. Grafik hasil pengukuran amonium dapat dilihat pada Gambar 6 berikut ini:

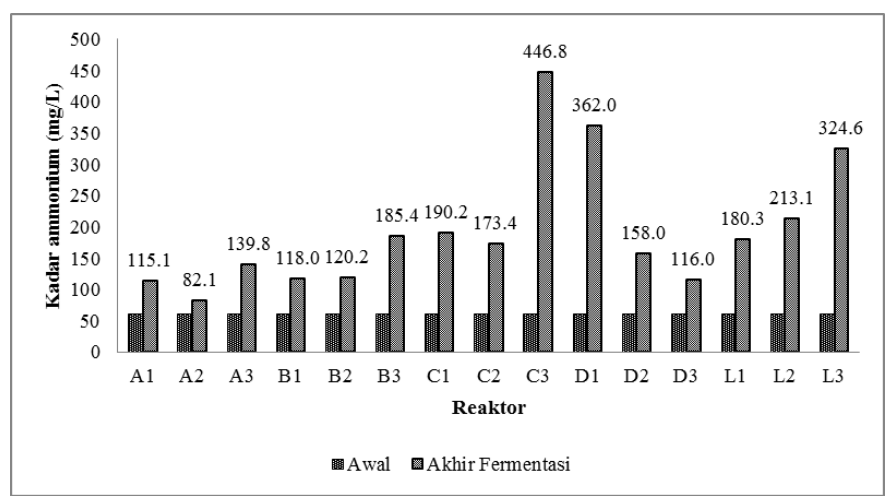

Gambar 6. Hasil uji ammonium.

Nilai amonium paling banyak pada reaktor C3 (penambahan bakteri starter cair $5 \mathrm{ml}$ dengan pengenceran 100x) yaitu sebesar 446,3 mg/l. Amonium meningkat dikarenakan adanya proses amonifikasi selama proses fermentasi anaerob. Amonifikasi adalah proses pembentukan amonia dari materi organik [11]. Hal ini sejalan dengan tujuan dari proses fermentasi. yaitu menaikkan nilai nitrogen yang diserap tanaman. Nilai amonium yang meningkat terjadi karena penguraian-penguraian zat organik pada lindi oleh mikroorganisme [12].

Pada kondisi anaerobik, terjadi mineralisasi senyawa nitrogen organik dimana nitrogen total hadir dalam wujud amonium dan amonia. Bahan organik terdekomposisi oleh mikroorganisme heterotrofik, sehingga konsentrasi amonium meningkat seiring dengan terjadinya degradasi bahan organik [13].

Untuk kadar nitrat tertinggi pada reaktor A2 (penambahan bakteri starter serbuk 0,5 gram dengan pengenceran $75 x$ ) yaitu sebesar 30,8 mg/l. Nitrat yang tinggi pada reaktor lindi kontrol disebabkan tidak adanya bakteri Azospirillum sp. yang tidak mengubah nitrat menjadi amonium sehingga proses nitrifikasi pada reaktor kontrol terjadi karena adanya bakteri nitrosomonas dan nitrosobacter.

Kenaikan nitrat selama proses fermentasi disebabkan kondisi anaerob, sehingga dapat terjadi reaksi oksidasi dari ammonia menjadi nitrat (proses nitrifikasi) [11]. Nitifikasi yaitu proses oksidasi dari nitrogen dalam ion amonium untuk memproduksi nitrat. Nitrifikasi dilakukan oleh bakteri genus Nitrosomonas dan Nitrobacter. Mikroba ini memperoleh energi dengan cara mengoksidasi amonium atau nitrit [14]. Keberadaan nitrat ini akan berlanjut pada tahap denitrifikasi yang akan dilakukan oleh bakteri Azospirillum sp hingga menghasilkan $\mathrm{N}_{2}$ bebas dan mengikat $\mathrm{N}_{2}$ saat berada di tumbuhan (saat pemberian pupuk ke tanaman) [15]. Sedangkan grafik hasil uji nitrat dapat dilihat pada Gambar 7 berikut: 


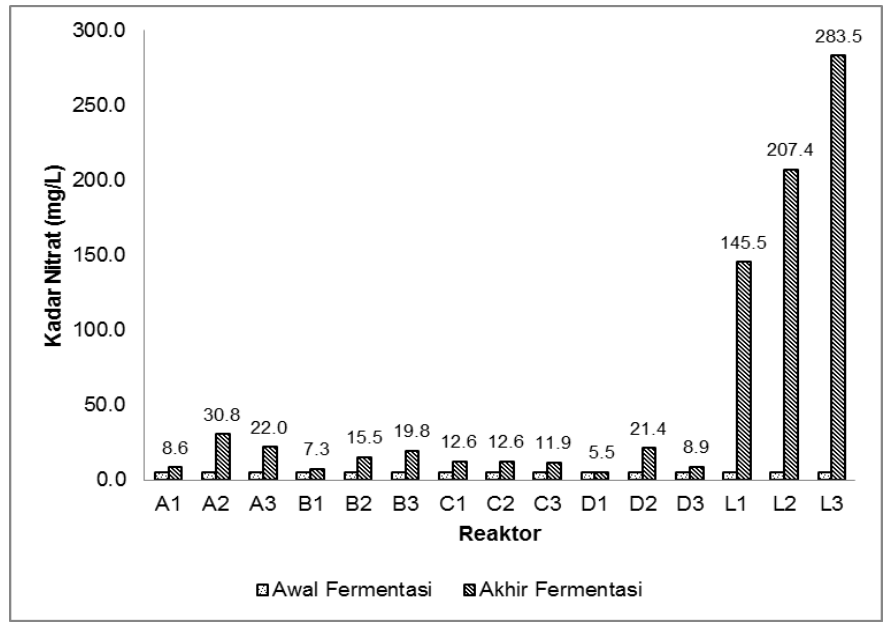

Gambar 7. Hasil uji nitrat.

Kemudian, hasil analisis pada parameter amonium nitrat ini akan diuji signifikansi dalam uji statistik. Uji statistik dilakukan dengan selang kepercayaan $\alpha=0,05$. Pada uji ini, akan dilihat pengaruh penambahan bakteri dan konsentrasi lindi terhadap hasil pupuk organik cair yang dilihat melalui peningkatan amonium dan nitrat yang dihasilkan. Uji signifikansi pada penelitian ini menggunakan ANOVA General Linear Model (GLM). Hasil uji menunjukkan interaksi antara penambahan bakteri starter baik serbuk maupun cair dan konsentrasi pengenceran lindi memiliki pengaruh signifikan terhadap peningkatan amonium dan nitrat. Kemudian untuk hasil uji statistik lanjutan dengan ANOVA General Linear Model (GLM), didapat reaktor yang memiliki mean tertinggi pada interactions plots adalah reaktor B3 dan C3. Yang artinya kedua reaktor tersebut memiliki pengaruh paling signifikan terhadap hasil peningkatan amonium dan nitrat selama proses fermentasi.

\section{F. Pengamatan Pertumbuhan Tanaman Uji}

Untuk tanaman cabai, kenaikan tinggi batang tertinggi pada reaktor kimia dan reaktor B3. Dimana pada reaktor B3 ini, mengandung jumlah koloni bakteri paling banyak untuk reaktor dengan penambahan bakteri dari bioaktovator serbuk, yaitu $30 \times 10^{8} \mathrm{cfu} / \mathrm{ml}$. Pupuk B3 adalah pupuk yang diberi perlakuan penambahan bakteri starter serbuk 1 gram dengan pengenceran 100 kali. Sehingga, penambahan jumlah bakteri sebesar 1 gram dengan pengenceran lindi yang tinggi dapat membuat jumlah koloni bakteri pada pupuk organik cair menjadi tinggi. Dan jumlah koloni yang tinggi ini berbanding lurus dengan kenaikan tinggi tanaman cabai.

Kenaikan tinggi tanaman cabai dengan pemberian pupuk starter cair tertinggi pada reaktor D2. Meskipun pada jumlah koloni yang terhitung pada hasil TPC yang tertinggi di reaktor D1, tetapi kenaikan pada reaktor D2 bisa lebih tinggi. Hal ini bisa dikarenakan jumlah bakteri yang bekerja mengikat $\mathrm{N}_{2}$ pada tanah di reaktor D2 bisa lebih efisien, meskipun jumlahnya tidak sebanyak D1. Sedangkan untuk reaktor kontrol (lindi tanpa bakteri), rata - rata kenaikan tinggi tanaman masih dibawah kenaikan tinggi rata - rata pada pupuk dengan starter cair maupun serbuk. Hal ini bisa disebabkan kandungan jumlah koloni bakteri yang masih terlalu kecil, sehingga selama proses pertumbuhan bakteri yang ada kurang bisa membantu proses penyerapan unsur - unsur hara yang dibutuhkan.

Terjadi penurunan jumlah daun dari awal pengamatan hingga hari ke-30. Meskipun sempat mengalami kenaikan pertumbuhan jumlah daun, namun ada tanaman yang daunnya banyak yang gugur. Hal ini disebabkan beberapa hal, dimana penyebab utamanya adalah tanaman cabai yang terserang penyakit (hama). Berdasarkan ciri - ciri hama yang teramati, kemungkinan tanaman cabai terserang hama kutu persik/aphid hijau (Myzus persicae Sulz) dan Thrips. tanaman menjadi mati [16]. Serangan hama tersebut menyebabkan tidak hanya pertumbuhan daun menjadi terhambat bahkan tidak tersisa sama sekali. Sehingga tidak bisa dianalisis terhadap pengaruh pemberian pupuknya.

Sedangkan pada tanaman terong, kenaikan tinggi batang tertinggi pada reaktor kimia dan reaktor A1 dan C1. Meskipun pada reaktor $\mathrm{A} 1$ dan $\mathrm{C} 1$ ini, mengandung jumlah koloni bakteri yang cukup kecil, namun jumlah bakteri yang ada bisa dengan maksimal menyerap kebutuhan unsur hara untuk tanaman. Sedangkan untuk reaktor kontrol (lindi tanpa bakteri), rata - rata kenaikan tinggi tanaman masih dibawah kenaikan tinggi rata - rata pada pupuk dengan starter cair maupun serbuk. Hal ini bisa disebabkan kandungan jumlah koloni bakteri yang masih terlalu kecil, sehsingga selama proses pertumbuhan bakteri yang ada kurang bisa membantu proses penyerapan unsur - unsur hara yang dibutuhkan. Keberadaan bakteri penambat $\mathrm{N}$ yang ditambahkan pada reaktor baik dalam bentuk serbuk maupun cair memberikan pengaruh penambahan jumlah koloni bakteri yang lebih besar dibandingkan dengan reaktor kontrol dimana lindi hanya diberikan pengenceran tanpa ada penambahan bakteri.

Pemberian pupuk selama 30 hari belum meningkatkan pertumbuhan daun lebih cepat, dibandingkan dengan pupuk kimia. Dikarenakan daun yang tumbuh dari terong memerlukan waktu yang cukup lama dalam pemunculan tunas daun baru. Sehingga, peningkatan jumlah daun cukup rendah. Bahkan, ada yang sempat mati dikarenakan layu sehingga jumlah daun tidak bertambah.

\section{KESIMPULAN/RINGKASAN}

Konsentrasi penambahan bakteri starter yang paling baik dalam menghasilkan pupuk cair lindi sesuai hasil penelitian yaitu B3 untuk reaktor dengan penambahan bioaktivator serbuk sedangkan untuk reaktor uji penambahan bioaktivator cair adalah D1. Berdasarkan interaksi antara faktor penambahan bakteri dan konsentrasi pengenceran lindi pada hasil uji signifikansi, menunjukkan bahwa reaktor B3 dan C3 memiliki pengaruh paling signifikan terhadap hasil peningkatan amonium dan nitrat pada akhir fermentasi.

Namun pada pertumbuhan tanaman, baik cabai maupun terong memilik perbedaan hasil terbaik dalam pengaruh pemberian pupuknya. Dimana jumlah koloni terbesar pada reaktor B3 dan D1 tidak menunjukkan hasil yang sesuai dengan pertumbuhan tanaman yang seharusnya pertumbuhannya batang maupun daun paling tinggi. Hal ini bisa dikarenakan meskipun jumlah koloni bakterinya sedikit, 
namun sudah mampu dengan maksimal memfiksasi $\mathrm{N}_{2}$ di udara.

Secara keseluruhan, fermentasi dengan penambahan bakteri telah mampu menurunkan kadar organik pada lindi dan bisa didapat hasil kandungan amonium dan nitrat serta peningkatan jumlah bakteri penambat $\mathrm{N}$ yang berpotensi dimanfaatkan sebagai puouk organik cair lindi.

\section{UCAPAN TERIMA KASIH}

Penulis Dania D. mengucapkan terima kasih kepada pihak pengelola SPA Rangkah Surabaya yang telah membantu dalam penyediaan bahan Tugas Akhir ini.

\section{DAFTAR PUSTAKA}

[1] Dharmayanti, "Pengaruh Pemberian Biourine dan Dosis Pupuk Anorganik (N,P,K) Terhadap Beberapa Sifat Kimia Tanah Pegok dan Hasil Tanaman Bayam (Amaranthus sp.)," E-Jurnal Agroekoteknologi Trop., vol. 2, no. 3 .

[2] S. Esplugas, S. Contreas, and D. Ollis, "Engineering aspects of the integration of chemical and biological oxidation: simule mechanistic models for the oxidation treatment," J. Environ. Eng.

[3] E. Hartati, "Studi pengolahan kandungan ion logam $(\mathrm{Fe}, \mathrm{Mn}, \mathrm{Cu}$, Zn) lindi sampah oleh zeolit," J. Sains MIPA, vol. 13, no. 1.

[4] P. Lingga and Marsono, Petunjuk penggunaan pupuk. Jakarta:
Penebar Swadaya.

[5] S. Mehrvarz and M. R. Chaichi, "Effect of phosphate solubilizing microorganisms and phosphorus chemical fertilizer on forage and grain quality of barely (Hordeum vulgare L.)," Am. J. Agric. Environ. Sci, vol. 3, no. 6, pp. 855-860.

[6] Nurhasanah, Pengolahan Lindi dan Potensi Pemanfaatannya sebagai Pupuk Cair untuk Mendukung Pengembangan TPA Sampah Lestari. Surabaya. .

[7] Nurosid, "Kemampuan azospirillum sp. Jg3 dalam menghasilkan lipase Pada medium campuran dedak dan onggok dengan Waktu inkubasi berbeda," Purwokerto.

[8] E. Riansyah and W. Putu, "Pemanfaatan Lindi Sampah Sebagai Pupuk Cair," J. Ilm. Tek. Lingkung., vol. 4, no. 1.

[9] D. Rilawati, "Kajian Penggunaan Boisca untuk Pemanfaatan Air Lindi (Leachate) Menjadi Pupuk Cair,” Universitas Negeri Sebelas Maret.

[10] N. Setiadewi and H. Welly, "Pengaruh tasiun peralihan antara terhadap pengelolaan sampah permukiman di kecamatan Tambaksari, Surabaya," Institut Teknologi Sepuluh Nopember.

[11] Z. A. Siddiqui, PGPR: Biocontrol and biofertilization. Netherland: Springer.

[12] G. Tchobanoglous, H. Theissen, and V. Samuel, Integrated Solid Waste Management Issue. New York: Mc Graw Hill.

[13] K. K. P. Tilak, K. V. B. R. and R. Dey, Microbes for sustainable agriculture. New Delhi: I.K International Publishing House Pvt. Ltd.

[14] Yuwono, Pupuk Organik Cair. Jakarta: Penebar Swadaya. 